\title{
Physical Activity and Sedentary Behaviors (Screen Time and Homework) Among Overweight or Obese Adolescents Before The COVID-19 Pandemic: A Cross-Sectional Observational Study in Yazd, Iran
}

Ali Mohammad Hadianfard

Ahvaz Jundishapur University of Medical sciences

Hassan Mozaffari-Khosravi

Shahid Sadoughi University of Medical Sciences

Majid Karandish

Ahvaz Jundishapur University of Medical Sciences

Maryam Azhdari ( $\square$ azhdari_mar@yahoo.com )

Shahid Sadoughi University of Medical Sciences

\section{Research Article}

Keywords: Overweight or obesity, adolescents, physical activity, sedentary behaviors, screen time

Posted Date: July 14th, 2021

DOI: https://doi.org/10.21203/rs.3.rs-668903/v1

License: (c) (i) This work is licensed under a Creative Commons Attribution 4.0 International License. Read Full License 


\section{Abstract \\ Background}

The growing number of adolescents who are overweight or obese (OW / OB) is a public concern. The present study was aimed to evaluate PA and sedentary behaviors (SB) (screen time (ST) and homework time (HT)) among Yazd OW/OB adolescents before the COVID-19 pandemic.

\section{Methods}

This cross-sectional study was performed among 510 students aged 12-16 in Yazd, Iran. The general information, physical activity (PA), and SB (ST and HT) were collected by interview based on the WHO standard questionnaire. Anthropometric data and daily energy intake (Energy) were assessed.

\section{Results}

There was a high prevalence of SB $>2 \mathrm{~h} /$ day (97.6), ST > 2h/day (70.3\%), overweight or obesity (40\%), abdominal obesity (36.9\%), low PA (29.8\%) among the students. The younger age $(p=0.014)$, energy $(p<0.001)$, no access to the yard $(p<0.001)$, family size $\leq 4(p=0.023)$, the commuting to school by motor vehicles $(p=0.001)$, the highest school days' HT ( $p=0.033)$ and SB $(p=0.021)$, and the highest weekends' HT among the students were the risk factors for $O W / O B$. The highest PA level was associated with a lower risk of OW/OB $(p<0.001)$. The findings were not the same in both sexes. Compared to the normal weight students, OW / OB spent more time on school days and weekdays for ST $(P<0.001), H T(P<0.001, P=0.005)$ and SB $(P<0.001)$, respectively. OW/OB students showed a higher weekends' ST $(p<0.001)$ and lower HT $(p=0.048)$ than normal-weight students.

\section{Conclusion}

The prevalence of SB, ST, OW/OB, and low PA were common. The school days and weekends' HT, the school days' SB and $\mathrm{HT}$, age, energy, $\mathrm{PA}$, and access to the yard, family size, and the commuting to school were related to the greater chances of $\mathrm{OW} / \mathrm{OB}$ students. Given that the expansion of online education and self-isolation in a new situation with COVID-19, it seems we will meet the worrying results.

\section{Background}

Worldwide obesity among adolescents is on the rise. Obese adolescents are more likely to remain obese in adulthood (1). The prevalence of overweight and obesity among children and adolescents aged 5-19 has risen more than 4 times from 1975 to 2016 with a similar rise among both boys and girls. According to a WHO report, the increasing prevalence of childhood obesity emanates from lifestyle changes (unhealthy dietary intake and physical inactivity (PA) patterns) in a society which leads to an energy imbalance (more calorie intake and low calories expended (2). There is a global trend toward unhealthy dietary habits, physical inactivity, and sedentary behaviors (SB) among adolescents. However, daily energy intake was lower in the normal-weight students than the overweight or obese students (1), breakfast energy was higher in the normal-weight students (3).

Some of the most important reasons for the tendency to physical inactivity include the sedentary nature of many forms of leisure, changing modes of transportation, and increasing urbanization (1). A study showed that more than 
$50 \%$ of the students (12-17 years) of the resident in Qatar reported a low PA and high screen time (ST) more than 2 hours ( $\geq 2 \mathrm{~h}$ ) on both weekdays and weekends. The prevalence of SB was higher on the weekends than weekdays. Moreover, the girl students had a more inactive pattern (low PA and high ST) than the boy students as well as Qatari students than non-Qatari students. The Qatari students and non-Qataris had more ST during the weekdays and weekends, respectively (4).

Watching TV/video/DVD and homework for $\geq 2 \mathrm{~h}$, and insufficient PA were related to Sri Lankan overweight adolescents aged 14-15 (5). The prevalence of overweight or obesity and using ST $\geq 2 \mathrm{~h}$ /day between U.S children or adolescents (6-17 years) was high (35.3\% and 44\%, respectively). In both genders, the high ST was related to low PA. The combined risk of low PA and high ST (inactive pattern) were shown at nearly two times higher than the risk of being overweight (6). A study on both Iranian girls and boys aged 13-18 years showed the prevalence of watching TV $\geq 2 \mathrm{~h}$ (57.22 and $57.57 \%$, respectively), using a personal computer (PC) $\geq 2 \mathrm{~h}$ (10.31 and 18.07\%, respectively), and low PA (39.34 and 34.5\%, respectively). Moreover, Iranian students with an unhealthy diet and overweight or obesity had a higher risk for higher watching TV, using a computer, and ST. The boys were at greater risk for excessive use of computers and ST (7). In another study on both Iranian girls and boys (from 30 provinces of Iran, 13-18 years), the prevalence of ST (TV and PC) $\geq 2 \mathrm{~h}$ (43.55 and 39.05\%), general obesity (5.43 and 6.7\%), abdominal obesity (17.58 and $19.23 \%$ ), and overweight (13.9 and 14.1\%) were reported, respectively (8). The results of a systematic review in 2019 showed high ST could be one of the risk factors of overweight/obesity in children and adolescents (9). The insufficient leisure-time PA (ILPA) was associated with the grade in both sexes, weekday ST, excessive use of smartphones during the weekday and weekend among the boys, studying tonight, having a work, family income, weekday ST and dissatisfaction with the own weight among the girls (10). Polish adolescents (11-13 years) revealed that only $17 \%$ of them had the most active pattern (both low ST and high PA) with higher adherence in the boys. Low PA (regardless of ST) was associated with overweight or central obesity (11).

However, the previous studies have pointed out the unfavorable impacts of physical inactivity and SB on the weight status among adolescents around the world, physical inactivity SB were affected by socioeconomic status, gender, race/ethnicity, and geographic characteristics, and age $(4,9-12)$. Therefore, it seems necessary to conduct the studies in each region. The present study was aimed to evaluate whether PA and SB related to the weight status among adolescents before the coronavirus disease 2019 (COVID-19) pandemic.

\section{Methods}

\section{Study design and Participants}

The data of the present cross-sectional study were gathered among the students of Yazd, located in the center of Iran from April 20, 2019, to Jane 3, 2019 (before the COVID-19 pandemic). A random multistage cluster sampling method was performed to select 510 students (12-16 years). The details for estimating the sample size were previously published $(3,13)$. The eligibility criteria included the students with normal or over weight and obesity and also completing written informed consent by both students and their parents. The students who were thin (Body mass index (BMI) $\leq-2$ Standard deviation (SD)), hospitalized within the last 6 months for any reason, used medicine such as narcotics and psychotropic, involved with the diseases such as hormonal impairment, cardiovascular disorders, malignancy were excluded from the study. A general questionnaire was used to collect the information including gender, age, family size, the education levels of father or mother, the access to the yard, the commuting to school, and grade $(7,14)$. The family size was considered based on the number of children and categorized into less and more than 4. The education level of the parents were categorized into 3 groups (literacy, under diploma/diploma, and college) (7). The students were asked to determine whether they have access to the yard. The commuting to school 
was categorized into a) walking or biking and b) motor vehicles (14). All questionnaires were conducted by the research-trained assistants.

ST, homework time (HT), and SB were assessed for the times of out of the schools $(7,8)$. SB was assessed by two questions about the duration of time they spend sitting when not at the school 1) how much do you spend on HT (online/ traditional education time, reading, and studying lessons)? and 2) how much time do you spend sitting to use ST tools (TV, computers, tablets, and smartphones)?

The purpose of ST tools use was categorized into 3 groups: 1) only education, 2) leisure/ entertainment, and 3) Both of them. Leisure or entertainment was explained to the students as follows: reading or listening for a fun time, talking with friends, and recreational ST (watching TV, video, and etc, time spent in front of a computer screen, smartphone, tablet for any reason). SB was calculated by summing up ST and HT per day (5).

According to the age of the students, the PA questionnaire for the adolescents (PAQ-A) or older children (PAQ-C) was used to assess the general levels of PA for the students (15). The score ranges for PAQ were from 1-5. The inactive, moderate, and active students scored between 1-1.9, 2-3.9, and 4-5, respectively (16).

Anthropometric information (weight, height, BMI, and waist circumstance (WC)) were measured in the morning before completing the questionnaires and the students were lightly dressed and without shoes. BMI $(\mathrm{kg} / \mathrm{m} 2)$ was calculated by this equation: weight $(\mathrm{kg}) /$ height $^{2}\left(\mathrm{~m}^{2}\right)$. BMI z-score was categorized into normal students (BMI between 1SD to $-2 S D)$ and overweight or obesity (BMI $\geq 1 S D)$ ) (17). Age-and sex-specific 90th percentile cut-offs of WC was used to categorize into 2 groups including normal (<90th percentile) and central/abdominal obesity ( $\geq 90$ th percentile) (18).

Daily energy intake was assessed by the average of three, 24-h dietary recalls ( 2 weekdays and 1 weekend) for each student, individually.

\section{Data analysis}

The analysis of quantifiable or categorical variables was conducted by means and standard deviations (SD) or frequency (number (\%)). The Kolmogorov-Smirnoff test was used to test the normality distribution of data to determine the parametric or non-parametric test. The comparison of the variables was used by t-test in both genders. Logistic regression was used to determine the influence of some variables on the overweight or obesity status. Adjusting was considered for the potential confounders including age, sex, grade, family size, access to the yard. SPSS statistical software package, version 26.0 (SPSS, Inc, Chicago, Illinois, USA), was applied for the statistical analyses. $\mathrm{P}<0.05$ was considered as statistically significant using 2-tailed tests.

\section{Results}

The participants (50.6\% male and $49.4 \%$ female) were randomly selected from six high schools of Yazd. The general characterizes of the students were reported in Table 1. Unfortunately, there was a high prevalence of SB $>2 \mathrm{~h} / \mathrm{day}$ (97.6), ST > 2h/day (70.3\%), overweight or obesity (40\%), abdominal obesity (36.9\%), and low PA (29.8\%) among the students. $44.5 \%$ of the families had more than two children. More than half of the students (53.9\%) did not access to the yard. The main purpose of $73.8 \%$ of students who use the ST tools was leisure or entertainment. $4.2 \%$ of the students used the ST tools only for the education. The commuting to school was motor vehicles in $54.7 \%$ of the students. About 56.3 and $67.1 \%$ of the mothers and fathers had a college education, respectively. 
Table 1

Basic characterizes of the study adolescents

\begin{tabular}{|c|c|c|}
\hline Variables & & Frequency (\%) \\
\hline \multirow[t]{2}{*}{$\operatorname{Sex}(N=510)$} & Boy & $258(50.6)$ \\
\hline & Girl & $252(49.4)$ \\
\hline \multirow[t]{3}{*}{ Grade $(N=510)$} & Seventh & $126(24.7)$ \\
\hline & Eighth & $168(32.9)$ \\
\hline & Ninth & $216(42.6)$ \\
\hline \multirow[t]{2}{*}{ Body Mass Index (BMI) $(\mathrm{N}=510)$} & Normal & $306(60)$ \\
\hline & Overweight or obesity & $204(40)$ \\
\hline \multirow[t]{2}{*}{ Waist Circumstance $(\mathrm{N}=510)$} & Normal & $322(63.1)$ \\
\hline & Abdominal obesity & $188(36.9)$ \\
\hline \multirow[t]{2}{*}{ Family size $(\mathrm{N}=510)$} & $\leq 4$ & $283(55.5)$ \\
\hline & $>4$ & $227(44.5)$ \\
\hline \multirow[t]{3}{*}{ Education levels of mother $(\mathrm{N}=498)$} & Literacy & $4(0.8)$ \\
\hline & Under diploma/Diploma & $207(40.6)$ \\
\hline & College & $287(56.3)$ \\
\hline \multirow[t]{3}{*}{ Education levels of father $(\mathrm{N}=504)$} & Literacy & $6(1.2)$ \\
\hline & Under diploma/Diploma & $156(30.6)$ \\
\hline & College & $342(67.1)$ \\
\hline \multirow[t]{2}{*}{ Access to the Yard $(\mathrm{N}=488)$} & Yes & $240(47.1)$ \\
\hline & No & $248(53.9)$ \\
\hline \multirow[t]{2}{*}{ Commuting to the school $(\mathrm{N}=510)$} & Walking or biking & $231(45.3)$ \\
\hline & Motor vehicles & $279(54.7)$ \\
\hline \multirow[t]{2}{*}{ Using screen time $(\mathrm{N}=504)$} & Yes & $499(99)$ \\
\hline & No & $5(1)$ \\
\hline \multirow[t]{3}{*}{ The purpose of screen time use $(\mathrm{N}=503)$} & Education & $21(4.2)$ \\
\hline & Leisure/ Entertainment & $371(73.8)$ \\
\hline & Both of them & $111(22)$ \\
\hline \multirow[t]{3}{*}{ Physical activity } & Low & $152(29.8)$ \\
\hline & Moderate & $183(35.9)$ \\
\hline & High & $175(34.3)$ \\
\hline
\end{tabular}


Overweight or obese boys reported the higher times for the school days' ST $(p=0.001), H T(p<0.001)$, and SB $(p<$ $0.001)$ compared to the normal-weight boys. Only ST was shown a significant increase among the overweight or obese boys on the weekends $(p=0.034)$. HT $(p=0.298)$ and SB $(p=0.4)$ showed no significant difference between normal and overweight or obese boys on the weekends. Moreover, overweight or obese boys reported a high on all week's ST ( $p<0.001), H T(p=0.003)$, and SB $(p<0.001)$. The PA levels were higher in normal-weight boys compared to the overweight or obese boys $(p<0.001)$ (Table 2$)$.

Table 2

The comparison of the sedentary and physical activities between the normal weight and overweight or obesity students by gender.

\begin{tabular}{|c|c|c|c|c|c|c|c|c|c|}
\hline \multirow[t]{2}{*}{ Variables } & \multicolumn{3}{|l|}{ Boy } & \multicolumn{3}{|c|}{ Girl } & \multicolumn{2}{|c|}{ Total } & \multirow[b]{2}{*}{$\begin{array}{l}\mathrm{P} \text { - } \\
\text { value }\end{array}$} \\
\hline & $\begin{array}{l}\text { Normal } \\
\text { weight }\end{array}$ & $\begin{array}{l}\text { Overweight } \\
\text { or obesity }\end{array}$ & $\begin{array}{l}\mathrm{P}- \\
\text { value }\end{array}$ & $\begin{array}{l}\text { Normal } \\
\text { weight }\end{array}$ & $\begin{array}{l}\text { Overweight } \\
\text { or obesity }\end{array}$ & $\begin{array}{l}\mathrm{P}- \\
\text { value }\end{array}$ & $\begin{array}{l}\text { Normal } \\
\text { weight }\end{array}$ & $\begin{array}{l}\text { Overweight } \\
\text { or obesity }\end{array}$ & \\
\hline \multicolumn{10}{|c|}{ Sedentary behaviors on school days } \\
\hline $\begin{array}{l}\text { Screen } \\
\text { time }\end{array}$ & $\begin{array}{l}119.6 \\
\pm 60.3\end{array}$ & $\begin{array}{l}146.32 \pm \\
64.4\end{array}$ & 0.001 & $\begin{array}{l}123.70 \\
\pm 56.4\end{array}$ & $\begin{array}{l}148.78 \pm \\
63.44\end{array}$ & 0.001 & $\begin{array}{l}121.67 \\
\pm 58.31\end{array}$ & $\begin{array}{l}147.50 \pm \\
63.78\end{array}$ & $\begin{array}{l}<.001 \\
0\end{array}$ \\
\hline $\begin{array}{l}\text { Homework } \\
\text { time }\end{array}$ & $\begin{array}{l}134.6 \\
\pm 43.26\end{array}$ & $\begin{array}{l}167.26 \pm \\
71.23\end{array}$ & $\hat{0} .001$ & $\begin{array}{l}139.48 \\
\pm 47.84\end{array}$ & $\begin{array}{l}154.9 \pm \\
73.32\end{array}$ & 0.044 & $\begin{array}{l}137.06 \\
\pm 45.61\end{array}$ & $\begin{array}{l}161.33 \pm \\
72.33\end{array}$ & <. 001 \\
\hline $\begin{array}{l}\text { Sedentary } \\
\text { behaviors } \\
\text { time }\end{array}$ & $\begin{array}{l}254.21 \\
\pm 73.56\end{array}$ & $\begin{array}{l}313.58 \pm \\
73.03\end{array}$ & $\hat{0} .001$ & $\begin{array}{l}263.18 \\
\pm 72.81\end{array}$ & $\begin{array}{l}303.67 \pm \\
76.49\end{array}$ & $\hat{0} .001$ & $\begin{array}{l}258.73 \\
\pm 73.2\end{array}$ & $\begin{array}{l}308.82 \pm \\
74.7\end{array}$ & < 0.001 \\
\hline \multicolumn{10}{|c|}{ Sedentary behaviors on weekends } \\
\hline $\begin{array}{l}\text { Screen } \\
\text { time }\end{array}$ & $\begin{array}{l}171.91 \\
\pm 75.57\end{array}$ & $\begin{array}{l}193.87 \pm \\
89.59\end{array}$ & 0.034 & $\begin{array}{l}169.48 \\
\pm 71.17\end{array}$ & $\begin{array}{l}214.9 \pm \\
91.75\end{array}$ & $\dot{0} 001$ & $\begin{array}{l}170.68 \\
\pm 73.27\end{array}$ & $\begin{array}{l}203.97 \pm \\
91.02\end{array}$ & $\begin{array}{l}<.001 \\
0.00\end{array}$ \\
\hline $\begin{array}{l}\text { Homework } \\
\text { time }\end{array}$ & $\begin{array}{l}185.07 \\
\pm 77.7\end{array}$ & $\begin{array}{l}174.62 \pm \\
81.32\end{array}$ & 0.298 & $\begin{array}{l}182.37 \\
\pm 73.49\end{array}$ & $\begin{array}{l}165 \pm \\
75.02\end{array}$ & 0.071 & $\begin{array}{l}183.71 \\
\pm 75.5\end{array}$ & $170 \pm 78.3$ & 0.048 \\
\hline $\begin{array}{l}\text { Sedentary } \\
\text { behaviors } \\
\text { time }\end{array}$ & $\begin{array}{l}356.97 \\
\pm \\
103.49\end{array}$ & $\begin{array}{l}368.49 \pm \\
114.05\end{array}$ & 0.4 & $\begin{array}{l}351.85 \\
\pm 98.99\end{array}$ & $\begin{array}{l}379.9 \pm \\
119.53\end{array}$ & $\hat{0} .001$ & $\begin{array}{l}354.39 \\
\pm \\
101.12\end{array}$ & $\begin{array}{l}373.97 \pm \\
116.57\end{array}$ & 0.051 \\
\hline \multicolumn{10}{|c|}{ Sedentary behaviors on all week } \\
\hline $\begin{array}{l}\text { Screen } \\
\text { time }\end{array}$ & $\begin{array}{l}134.55 \\
\pm 54.13\end{array}$ & $\begin{array}{l}159.91 \pm \\
57.85\end{array}$ & $\hat{0} .001$ & $\begin{array}{l}136.78 \\
\pm 48.10\end{array}$ & $\begin{array}{l}167.67 \pm \\
54.47\end{array}$ & $\hat{0} .001$ & $\begin{array}{l}135.67 \\
\pm 51.11\end{array}$ & $\begin{array}{l}163.64 \pm \\
56.25\end{array}$ & $\begin{array}{l}<.001 \\
0.00\end{array}$ \\
\hline $\begin{array}{l}\text { Homework } \\
\text { time }\end{array}$ & $\begin{array}{l}149.02 \\
\pm 39.21\end{array}$ & $\begin{array}{l}169.37 \pm \\
60.27\end{array}$ & 0.003 & $\begin{array}{l}151.73 \\
\pm 43.86\end{array}$ & $\begin{array}{l}157.78 \pm \\
54.85\end{array}$ & 0.359 & $\begin{array}{l}150.39 \\
\pm 41.57\end{array}$ & $\begin{array}{l}163.8 \pm \\
57.88\end{array}$ & 0.005 \\
\hline $\begin{array}{l}\text { Sedentary } \\
\text { behaviors } \\
\text { time }\end{array}$ & $\begin{array}{l}283.57 \\
\pm 67.12\end{array}$ & $\begin{array}{l}329.27 \pm \\
60.8\end{array}$ & $\hat{0} .001$ & $\begin{array}{l}288.51 \\
\pm 63.87\end{array}$ & $\begin{array}{l}325.45 \pm \\
63.00\end{array}$ & $\hat{0} .001$ & $\begin{array}{l}286.06 \\
\pm 65.44\end{array}$ & $\begin{array}{l}327.45 \pm \\
61.75\end{array}$ & < 0.001 \\
\hline $\begin{array}{l}\text { Physical } \\
\text { Activity }\end{array}$ & $\begin{array}{l}3.58 \pm \\
1.32\end{array}$ & $1.81 \pm 0.96$ & <. 001 & $\begin{array}{l}3.16 \pm \\
1.44\end{array}$ & $1.65 \pm 0.97$ & <. 001 & $\begin{array}{l}3.36 \pm \\
1.4\end{array}$ & $1.73 \pm 0.97$ & $\begin{array}{l}<.001 \\
0.00\end{array}$ \\
\hline
\end{tabular}

Among overweight and obese girls, the school days' ST $(p=0.001), H T(p=0.044)$, and SB $(p<0.001)$ were higher than normal-weight girls, significantly. The weekends' ST and SB $(p<0.001)$ were shown a significant increase in the 
overweight and obese girls. A significant difference was not reported for the weekends' HT between normal-weight and overweight or obese girls. Higher times on all week' ST and SB and lower PA levels were found in the overweight or obese girls compared to the normal-weight girls $(p<0.001)($ Table 2$)$.

In comparison to the normal-weight students, all overweight or obese students spent more time on ST $(p<0.001)$, HT $(p<0.001$ and 0.005$)$, and SB $(p<0.001)$ on the school days and all week, respectively. However, the overweight or obese students showed a significant enhancement on the weekends' ST $(p<0.001)$, they spent lower time on the weekends' HT ( $p=0.048)$. The weekends' SB was not shown any significant difference between the normal-weight and overweight or obese students $(p=0.051)$. The PA levels were more in the normal-weight students than overweight or obese students $(p<0.001)$ (Table 2$)$.

It is worth that the association of the independent variables with abdominal obesity in the logistic regression model was performed and their results were similar to overweight or obesity. Therefore, the relevant data on abdominal obesity was not shown in the present paper. In the crude analyses, more daily energy intake $(p<0.001)$, the smaller family size $(\leq 4)(p<0.001)$, no access to the yard $(p<0.001)$, the commuting to school by motor vehicles $(p<0.001)$, the quartile $3(p<0.001)$ and $4(p=0.003)$ of the school days' ST, the quartile 3 and 4 school days' HT $(p<0.001)$, and the quartile $3(p=0.002)$ and $4(p<0.001)$ of the school days' SB times on the school days, the quartile 4 of ST on the weekends $(p<0.001)$, the quartile $3(p=0.002)$ and $4(p<0.001)$ of ST on the weekends, the quartile $3(p=0.034)$ and 4 ( $p=0.021)$ of HT on the weekends, and the quartile 3 and 4 of SB time on all week $(p<0.001)$ were associated to overweight or obesity among the students. Moreover, the low risk of overweight or obesity was found in moderate ( $p=$ $0.001)$ and high $(p<0.001)$ levels of PA (Table 3$)$. 
Table 3

Association of independent variables with overweight or obesity in the logistic regression model

\begin{tabular}{|c|c|c|c|c|}
\hline Variables & Crude OR $(95 \% \mathrm{Cl})$ & P-value & Adjusted OR (95\% Cl)* & P-value \\
\hline Age (year) & $0.98(0.77,1.237)$ & 0.809 & $0.59(0.39,0.9)$ & 0.014 \\
\hline \multicolumn{5}{|l|}{ Sex (male) } \\
\hline Female & $0.93(0.647,1.307)$ & 0.611 & $1.52(0.76,3.02)$ & 0.234 \\
\hline Daily energy intake & $1.003(1.002,1.003)$ & $<0.001$ & $1.003(1.002,1.004)$ & $<0.001$ \\
\hline \multicolumn{5}{|l|}{ family Size ( $\leq 4)$} \\
\hline $4<$ & $0.32(0.21,0.49)$ & $<0.001$ & $0.48(0.26,0.9)$ & 0.023 \\
\hline \multicolumn{5}{|c|}{ Access to the Yard (No) } \\
\hline Yes & $0.21(0.14,0.31)$ & $<0.001$ & $0.2(0.1,0.38)$ & $<0.001$ \\
\hline \multicolumn{5}{|c|}{ Commuting to school by (Public/ personal vehicles) } \\
\hline Foot or bicycle & $0.241(0.16,0.36)$ & $<0.001$ & $0.34(0.19,0.64)$ & 0.001 \\
\hline \multicolumn{5}{|c|}{ Schooldays. Screen time quartile (1) } \\
\hline 2 & $0.9(0.56,1.42)$ & 0.642 & $0.21(0.06,0.8)$ & 0.022 \\
\hline 3 & $6.5(3.54,11.93)$ & $<0.001$ & $2.23(0.34,14.44)$ & 0.4 \\
\hline 4 & $2.24(1.31,3.82)$ & 0.003 & $0.71(0.08,6.77)$ & 0.77 \\
\hline \multicolumn{5}{|c|}{ Schooldays Homework time quartile (1) } \\
\hline 3 & $0.38(0.24,0.60)$ & $<0.001$ & $0.61(0.23,1.63)$ & 0.323 \\
\hline 4 & $5.25(3.06,9.00)$ & $<0.001$ & $7.11(1.17,43.28)$ & 0.033 \\
\hline \multicolumn{5}{|c|}{ Schooldays Sedentary behaviors quartile (1) } \\
\hline 2 & $1.63(0.87,3.04)$ & 0.128 & $3.23(1.03,10.11)$ & 0.044 \\
\hline 3 & $2.03(1.29,3.21)$ & 0.002 & $2.38(0.6,9.4)$ & 0.215 \\
\hline 4 & $7.81(4.56,13.37)$ & $<0.001$ & $10.13(1.42,72.28)$ & 0.021 \\
\hline \multicolumn{5}{|c|}{ Weekends. Screen time quartile (1) } \\
\hline 2 & $1.18(0.72,1.91)$ & 0.511 & $1.98(0.75,5.2)$ & 0.17 \\
\hline 3 & $1.54(0.92,2.58)$ & 0.101 & $1.48(0.43,5.15)$ & 0.533 \\
\hline 4 & $2.99(1.76,5.07)$ & $<0.001$ & $3.28(0.62,17.24)$ & 0.16 \\
\hline \multicolumn{5}{|c|}{ Weekends. Homework time quartile (1) } \\
\hline 2 & $0.73(0.47,1.15)$ & 0.182 & $1.52(0.55,4.16)$ & 0.418 \\
\hline 3 & $1.06(0.65,1.74)$ & 0.810 & $3.82(1.12,13.01)$ & 0.032 \\
\hline 4 & $0.63(0.36,1.09)$ & 0.096 & $5.55(1.04,29.47)$ & 0.044 \\
\hline
\end{tabular}




\begin{tabular}{|c|c|c|c|c|}
\hline Variables & Crude OR $(95 \% \mathrm{Cl})$ & P-value & Adjusted OR (95\% Cl)* & P-value \\
\hline \multicolumn{5}{|c|}{ Weekends. Sedentary behaviors quartile (1) } \\
\hline 2 & $0.99(0.60,1.64)$ & 0.981 & $0.69(0.24,1.98)$ & 0.493 \\
\hline 3 & $0.84(0.50,1.41)$ & 0.510 & $0.42(0.1,1.76)$ & 0.247 \\
\hline 4 & $1.2(0.72,1.99)$ & 0.491 & $0.27(0.04,1.85)$ & 0.184 \\
\hline \multicolumn{5}{|c|}{ All week. Screen time quartile (1) } \\
\hline 2 & $1.17(0.69,1.98)$ & 0.551 & $1.8(0.53,6.04)$ & 0.344 \\
\hline 3 & $2.26(1.34,3.81)$ & 0.002 & $2.6(0.43,15.9)$ & 0.3 \\
\hline 4 & $3.11(1.83,5.29)$ & $<0.001$ & $1.59(0.144,17.32)$ & 0.708 \\
\hline \multicolumn{5}{|c|}{ All week. Homework time quartile (1) } \\
\hline 2 & $0.8(0.49,1.31)$ & 0.369 & $1.1(0.42,2.89)$ & 0.841 \\
\hline 3 & $0.57(0.34,0.96)$ & 0.034 & $0.77(0.21,2.82)$ & 0.689 \\
\hline 4 & $1.79(1.09,2.94)$ & 0.021 & $0.44(0.06,3.27)$ & 0.418 \\
\hline \multicolumn{5}{|c|}{ All week. Sedentary behaviors quartile (1) } \\
\hline 2 & $1.57(0.92,2.7)$ & 0.099 & $1.76(0.59,5.18)$ & 0.308 \\
\hline 3 & $2.78(1.62,4.77)$ & $<0.001$ & $0.83(0.16,4.35)$ & 0.824 \\
\hline 4 & $5.14(2.99,8.83)$ & $<0.001$ & $0.52(0.05,4.93)$ & 0.567 \\
\hline \multicolumn{5}{|c|}{ All week. Physical activity (low) } \\
\hline Moderate & $0.485(0.311,0.757)$ & 0.001 & $0.426(0.207,0.874)$ & 0.020 \\
\hline High & $0.033(0.016,0.066)$ & $<0.001$ & $0.039(0.013,0.118)$ & $<0.001$ \\
\hline
\end{tabular}

After adjusted age, sex, grade, family size, and access to the yard effects, the association between the independent variables and overweight or obesity was re-evaluated. In the adjusted analyses, there were higher chances of overweight or obesity for all students at a younger age $(p=0.014)$, more daily energy $(p<0.001)$, the smaller family size $(\leq 4)(p=0.023)$, no access to the yard $(p<0.001)$, the commuting to school by motor vehicles $(p=0.001)$, the quartile 4 of the school days' HT ( $p=0.033)$, the quartile $2(p=0.044)$ and $4(p=0.021)$ of the school days' $S B$, and the quartile $3(p=0.032)$ and $4(p=0.044)$ of the weekends' HT. Moreover, low risk of overweight or obesity was presented among the students with the moderate $(p=0.001)$ and high $(p<0.001)$ levels of PA and lower school days' ST $(p=$ 0.022) (Table 3).

In crude analyses, the boys showed a greater risk of overweight or obesity was related to more daily energy intake ( $p<$ $0.001)$, the smaller family size $(\leq 4)(p=0.008)$, no access to the yard $(p<0.001)$, the commuting to school by motor vehicles $(p<0.001)$, the quartile $3(p<0.001)$ and $4(p=0.047)$ of the school days' ST on, the quartile $3(p=0.004)$ and $4(p<0.001)$ of the school days' HT, the quartile $3(p=0.012)$ and $4(p<0.001)$ of the school days' SB, the quartile 4 of the weekends ST ( $p=0.043)$, the quartile 4 of all week' ST $(p=0.017)$, the quartile 4 of all week's HT $(p=0.01)$, and the quartile $3(p=0.021)$ and $4(p<0.001)$ of all week's SB times. Low risk of overweight or obesity was reported in the 
boys with moderate $(p=0.004)$ and high $(p<0.001)$ levels of PA and the quartile 3 of HT on the school days $(p=$ 0.004) (Table 4). 
Table 4

Association of independent variables with overweight or obesity in the logistic regression model in boys

\begin{tabular}{|c|c|c|c|c|}
\hline Variables & Crude OR $(95 \% \mathrm{Cl})$ & P-value & Adjusted OR (95\% Cl)* & P-value \\
\hline Age (year) & $0.837(0.6,1.167)$ & 0.294 & $0.401(0.188,0.858)$ & 0.018 \\
\hline Daily energy intake & $1.002(1.001,1.003)$ & $<0.001$ & $1.003(1.002,1.004)$ & $<0.001$ \\
\hline \multicolumn{5}{|l|}{ Family Size $(\leq 4)$} \\
\hline $400<$ & $0.462(0.262,0.814)$ & 0.008 & $4.419(1.254,15.575)$ & 0.021 \\
\hline \multicolumn{5}{|c|}{ Access to the Yard (No) } \\
\hline Yes & $0.185(0.103,0.332)$ & $<0.001$ & $0.248(0.075,0.822)$ & 0.023 \\
\hline \multicolumn{5}{|c|}{ Commuting to the school (Public/ personal vehicles) } \\
\hline Foot or bicycle & $0.244(0.143,0.416)$ & $<0.001$ & $1.083(0.367,3.195)$ & 0.885 \\
\hline \multicolumn{5}{|c|}{ Schooldays. Screen time quartile (1) } \\
\hline 2 & $0.892(0.468,1.7)$ & 0.728 & $0.174(0.023,1.303)$ & 0.089 \\
\hline 3 & $5.793(2.483,13.517)$ & $<0.001$ & $3.430(0.181,64.908)$ & 0.411 \\
\hline 4 & $2.069(1.008,4.245)$ & 0.047 & $0.507(0.015,17.063)$ & 0.705 \\
\hline \multicolumn{5}{|c|}{ Schooldays. Homework time quartile (1) } \\
\hline 3 & $0.378(0.197,0.727)$ & 0.004 & $0.2(0.035,1.144)$ & 0.070 \\
\hline 4 & $7.389(3.302,6.535)$ & $<0.001$ & $1.5(0.104,21.562)$ & 0.765 \\
\hline \multicolumn{5}{|c|}{ Schooldays. Sedentary behaviors quartile (1) } \\
\hline 2 & $1.867(0.808,4.31)$ & 0.144 & $11.303(1.738,73.504)$ & 0.011 \\
\hline 3 & $2.333(1.205,4.519)$ & 0.012 & $1.76(0.189,16.432)$ & 0.620 \\
\hline 4 & $10.37(4.767,22.561)$ & $<0.001$ & $2.701(0.091,79.897)$ & 0.565 \\
\hline \multicolumn{5}{|c|}{ Weekends. Screen time quartile (1) } \\
\hline 2 & $1.192(0.62,2.294)$ & 0.598 & $2.729(0.491,15.168)$ & 0.251 \\
\hline 3 & $1.382(0.668,2.86)$ & 0.383 & $0.799(0.103,6.218)$ & 0.830 \\
\hline 4 & $2.12(1.025,4.386)$ & 0.043 & $2.316(0.136,39.448)$ & 0.562 \\
\hline \multicolumn{5}{|c|}{ Weekends. Homework time quartile (1) } \\
\hline 2 & $0.707(0.369,1.354)$ & 0.295 & $0.93(0.187,4.616)$ & 0.929 \\
\hline 3 & $1.161(0.582,2.316)$ & 0.672 & $1.559(0.232,10.502)$ & 0.648 \\
\hline 4 & $0.682(0.331,1.404)$ & 0.299 & $1.215(0.096,15.325)$ & 0.881 \\
\hline \multicolumn{5}{|c|}{ Weekends. Sedentary behaviors quartile (1) } \\
\hline 2 & $0.963(0.467,1.984)$ & 0.919 & $0.481(0.097,2.396)$ & 0.372 \\
\hline
\end{tabular}




\begin{tabular}{|c|c|c|c|c|}
\hline Variables & Crude OR (95\%Cl) & P-value & Adjusted OR (95\% Cl)* & P-value \\
\hline 3 & $0.869(0.440,1.718)$ & 0.687 & $0.209(0.02,2.232)$ & 0.195 \\
\hline 4 & $0.626(0.301,1.301)$ & 0.21 & $0.153(0.008,2.981)$ & 0.215 \\
\hline \multicolumn{5}{|c|}{ All week. Screen time quartile (1) } \\
\hline 2 & $0.955(0.463,1.969)$ & 0.9 & $0.826(0.121,5.623)$ & 0.845 \\
\hline 3 & $2.026(0.997,4.114)$ & 0.051 & $1.944(0.094,40.201)$ & 0.667 \\
\hline 4 & $2.39(1.166,4.899)$ & 0.017 & $1.63(0.028,94.137)$ & 0.813 \\
\hline \multicolumn{5}{|c|}{ All week. Homework time quartile (1) } \\
\hline 2 & $0.858(0.424,1.738)$ & 0.671 & $2.887(0.518,16.075)$ & 0.226 \\
\hline 3 & $0.473(0.224,1)$ & 0.05 & $1.736(0.21,14.323)$ & 0.608 \\
\hline 4 & $2.471(1.238,4.933)$ & 0.01 & $8.549(0.304,240.721)$ & 0.208 \\
\hline \multicolumn{5}{|c|}{ All week. Sedentary behaviors quartile (1) } \\
\hline 2 & $1.884(0.889,3.993)$ & 0.098 & $1.057(0.199,5.625)$ & 0.948 \\
\hline 3 & $2.476(1.148,5.339)$ & 0.021 & $0.392(0.025,6.11)$ & 0.504 \\
\hline 4 & $6.19(2.827,13.556)$ & $<0.001$ & $1.536(0.03,78.886)$ & 0.831 \\
\hline \multicolumn{5}{|c|}{ All week. Physical activity (low) } \\
\hline Moderate & $0.359(0.179,0.723)$ & 0.004 & $0.132(0.04,0.437)$ & 0.001 \\
\hline High & $0.022(0.008,0.061)$ & $<0.001$ & $0.004(0.001,0.034)$ & $<0.001$ \\
\hline
\end{tabular}

In adjusted analyses, a greater risk of overweight or obesity was related to younger age $(p=0.018)$, more daily energy intake $(p<0.001)$, the family size less than $4(p=0.021)$, no access to the yard $(p=0.023)$, and the quartile 2 of SB times on the school days $(p=0.011)$. The moderate $(p=0.001)$ and high $(p<0.001)$ levels of PA were associated with the lower risk of overweight and obesity among the boys (Table 4 ).

In crude analyses, the girls showed a greater risk of overweight or obesity was related to more daily energy intake ( $p<$ $0.001)$, the smaller family size $(\leq 4)(p<0.001)$, no access to the yard $(p<0.001)$, the commuting to school by motor vehicles $(p<0.001)$, the quartile $3(p<0.001)$ and $4(p=0.026)$ of the school days' ST, the quartile $3(p=0.004)$ and 4 $(p<0.001)$ of the school days' HT, the quartile 4 of the school days' SB $(p<0.001)$, the quartile $3(p=0.015)$ and $4(p<$ $0.001)$ of all week's ST, and the quartile $3(p=0.003)$ and $4(p<0.001)$ of all week's SB. In addition, the girls with moderate $(p=0.046)$ and high $(p<0.001)$ levels of PA were shown a low risk of overweight and obesity (Table 5$)$. 
Table 5

Association of independent variables with overweight or obesity in the logistic regression model in girls.

\begin{tabular}{|c|c|c|c|c|}
\hline Variables & Crude OR $(95 \% \mathrm{Cl})$ & P-value & Adjusted OR (95\% Cl)* & P-value \\
\hline Age (year) & $1.115(0.76,1.635)$ & 0.578 & $1.081(0.411,2.844)$ & 0.874 \\
\hline Daily energy intake & $1.006(1.005,1.008)$ & $<0.001$ & $1.007(1.004,1.009)$ & $<0.001$ \\
\hline \multicolumn{5}{|l|}{ Family Size $(\leq 4)$} \\
\hline $4<$ & $0.221(0.12,0.407)$ & $<0.001$ & $0.703(0.175,2.82)$ & 0.619 \\
\hline \multicolumn{5}{|c|}{ Access to the Yard (No) } \\
\hline Yes & $0.206(0.119,0.355)$ & $<0.001$ & $0.227(0.058,0.893)$ & 0.034 \\
\hline \multicolumn{5}{|c|}{ Commuting to the school (Public/ personal vehicles) } \\
\hline Foot or bicycle & $0.225(0.123,0.41)$ & $<0.001$ & $0.594(0.142,2.482)$ & 0.475 \\
\hline \multicolumn{5}{|c|}{ Schooldays. Screen time quartile (1) } \\
\hline 2 & $0.929(0.474,1.819)$ & 0.829 & $0.190(0.016,2.198)$ & 0.184 \\
\hline 3 & $7.429(3.091,7.855)$ & $<0.001$ & $1.158(0.024,54.901)$ & 0.941 \\
\hline 4 & $2.476(1.112,5.514)$ & 0.026 & $0.578(0.004,85.199)$ & 0.830 \\
\hline \multicolumn{5}{|c|}{ Schooldays. Homework time quartile (1) } \\
\hline 3 & $0.385(0.2,0.74)$ & 0.004 & $0.5(0.067,3.735)$ & 0.5 \\
\hline 4 & $3.791(1.815,7.917)$ & $<0.001$ & $736.588(1.118,485356.584)$ & 0.046 \\
\hline \multicolumn{5}{|c|}{ Schooldays. Overall Sedentary behaviors times quartile (1) } \\
\hline 2 & $1.375(0.53,3.564)$ & 0.512 & $2.152(0.155,29.866)$ & 0.568 \\
\hline 3 & $1.793(0.954,3.372)$ & 0.070 & $5.178(0.371,72.241)$ & 0.221 \\
\hline 4 & $5.867(2.77,12.426)$ & $<0.001$ & $5.183(0.113,238.025)$ & 0.399 \\
\hline \multicolumn{5}{|c|}{ Weekends. Screen time quartile (1) } \\
\hline 2 & $1.163(0.564,2.397)$ & 0.682 & $2.215(0.317,15.459)$ & 0.422 \\
\hline 3 & $1.768(0.842,0.713)$ & 0.132 & $4.851(0.33,71.214)$ & 0.249 \\
\hline 4 & $4.343(1.998,9.441)$ & $<0.001$ & $53.256(1.773,1599.286)$ & 0.022 \\
\hline \multicolumn{5}{|c|}{ Weekends. homework time quartile (1) } \\
\hline 2 & $0.764(0.405,1.439)$ & 0.404 & $5.176(0.403,66.498)$ & 0.207 \\
\hline 3 & $0.974(0.479,1.978)$ & 0.941 & $53.685(2.619,1100.448)$ & 0.010 \\
\hline 4 & $0.555(0.239,1.288)$ & 0.171 & $110.577(1.843,6633.313)$ & 0.024 \\
\hline \multicolumn{5}{|c|}{ Weekends. Overall sedentary behaviors times quartile (1) } \\
\hline 2 & $0.725(0.353,1.489)$ & 0.381 & $0.326(0.034,3.119)$ & 0.331 \\
\hline
\end{tabular}




\begin{tabular}{|c|c|c|c|c|}
\hline Variables & Crude OR $(95 \% \mathrm{Cl})$ & P-value & Adjusted OR (95\% Cl)* & P-value \\
\hline 3 & $0.778(0.380,1.592)$ & 0.492 & $0.072(0.002,2.076)$ & 0.125 \\
\hline 4 & $0.784(0.389,1.58)$ & 0.496 & $0.03(0.000,3.099)$ & 0.139 \\
\hline \multicolumn{5}{|c|}{ All week. Screen time quartile (1) } \\
\hline 2 & $1.513(0.699,3.272)$ & 0.293 & $15.83(1.259,198.978)$ & 0.032 \\
\hline 3 & $2.647(1.212,5.78)$ & 0.015 & $36.837(0.967,1403.868)$ & 0.052 \\
\hline 4 & $4.286(1.926,9.537)$ & $<0.001$ & $22.237(0.097,5090.267)$ & 0.263 \\
\hline \multicolumn{5}{|c|}{ All week. homework/ business time quartile (1) } \\
\hline 2 & $0.743(0.371,1.486)$ & 0.401 & $0.286(0.031,2.650)$ & 0.271 \\
\hline 3 & $0.679(0.33,1.399)$ & 0.294 & $0.430(0.024,7.824)$ & 0.568 \\
\hline 4 & $1.249(0.609,2.561)$ & 0.544 & $0.009(0.000,4.794)$ & 0.141 \\
\hline \multicolumn{5}{|c|}{ All week. Overall sedentary behaviors times quartile (1) } \\
\hline 2 & $1.272(0.582,2.779)$ & 0.547 & $0.602(0.06,6.053)$ & 0.667 \\
\hline 3 & $3.138(1.462,6.736)$ & 0.003 & $0.146(0.004,5.151)$ & 0.290 \\
\hline 4 & $4.333(2.046,0.176)$ & $<0.001$ & $0.025(0.000,2.061)$ & 0.101 \\
\hline \multicolumn{5}{|c|}{ All week. Physical activity (low) } \\
\hline Moderate & $0.538(0.292,0.989)$ & 0.046 & $1.25(0.276,5.66)$ & 0.772 \\
\hline High & $0.041(0.015,0.112)$ & $<0.001$ & $0.069(0.009,0.518)$ & 0.009 \\
\hline
\end{tabular}

In adjusted analyses, a greater risk of overweight or obesity was related to more daily energy intake $(p<0.001)$, no access to the yard $(p=0.034)$, the quartile 4 of the school days' $H T(p=0.046)$, the quartile $3(p=0.01)$ and $4(p=$ $0.024)$ of the weekends' HT, the quartile 2 of all week ST $(p=0.032)$. The highest levels of PA were associated with a low risk of overweight and obesity in the girls $(p=0.009)$ (Table 5$)$.

\section{Discussion}

The present study evaluated the association of SB, PA, and weight status among the Yazd students aged 12-16 years before the COVID-19. The current findings were shown the high prevalence of SB, ST, overweight or obesity, abdominal obesity, and physical inactivity among the Yazd students. Gholami and et al.(14) observed a $31.5 \%$ of prevalence of overweight and obesity among the Yazd students aged 9-13 years. The present findings showed a higher prevalence of overweight, obesity, and low PA rather than the study conducted by Gholami.

However, all normal-weight students spent less time on the school days and all week's ST, HT, and SB than overweight or obese ones, they spent a little more time on the weekends' HT. Moreover, overweight or obese students showed an increment of weekends' SB but it was no significant. The higher chance of overweight or obesity among Yazd students was related to the younger age, high energy intake, smaller family size, no access to the yard, the commuting to school by motor vehicles, higher school days' HT, the school days' SB, and the weekends' HT and lack of moderate 
and high PA levels. A lower school days' ST was inversely related to overweight or obesity. The boy students with overweight or obesity spent more time on the school days and week's ST, HT, and SB and the weekends' ST than the normal-weight boys. Moreover, higher chances of overweight or obesity were related to the younger age, high energy intake, smaller family size, no access to the yard, the quartile 2 of the school days' SB, and lack of moderate and high PA levels. In the girl students, there was a higher risk of overweight or obesity for high energy intake, no access to the yard, spending more time on the school days' HT and the weekends' HT, the quartile 2 of the week's ST and lack of the high PA levels.

However, Kelishadi et al.(8) showed physical inactivity $\geq 2$ times in the girl than boy Iranian students aged 13-18 y, the analysis of total students were near the results of the present study. Moreover, they reported a lower prevalence of general and abdominal obesity than Yazd students. The results of two published studies (2020) by Amiri et al. (19) and Khazaei et al. (20) presented an increasing trend of low PA among Iranian adolescents across urban and rural areas and obesity among Iranian children and adolescents, respectively.

In agreement with our results, Kelishadi et al. (5) illustrated there was a higher BMI among physically inactive Iranian children and adolescents. But their findings of the positive association between watching TV or using a PC $\geq 2$ hours/day and PA were the opposite of the current study. The results of a meta-analysis (2019) showed that ST especially watching TV and using $P C \geq 2 \mathrm{~h}$ /day was related to overweight or obesity among children and adolescents (9). In accordance with our results, Omorou et al. presented that overweight and obesity in French adolescents were related to SB rather than PA (12). Some SB (watching TV, Video/DVD, and Homework $\geq 2 \mathrm{~h} /$ day), insufficient PA, and high-calorie foods related to a high risk of overweight among Sri Lanka students aged 14-15 y (5). However, their results were similar to the current study, there was not any data for the school days or weekends.

As our results showed, there was a positive relationship between younger age and smaller family size with overweight or obesity in the boys and all the students but no significant difference was found between family size and age with weight status among the girls. In compliance with our results, Mozafarian et al.(7) illustrated that there was a negative association between the children number and spending time for SB. After adjusted BMl effects, younger age was related to insufficient PA in Brazilian boys (14-18y) but not in the girls (10).

Among Irish students aged 8-11 y, a higher risk of overweight or obesity was linked to the low PA and a high SB time on all week, weekdays, and weekends. Independent of total SB time, a high risk of overweight or obesity was related to spent lower time at the PA (21). Our results showed a higher chance of overweight or obesity among the students is relevant to more time on the school days' SB, HT, and ST and weekends' HT. However, independent of PA, an increased chance of overweight or obesity was associated with ST but not total SB time among Irish students aged 8-11 years (21). In line with the present results, Górnicka et al.(11) illustrated that higher PA reverses the trend of overweight.

Gholami et al. presented that the Yazd students who used motor vehicles had a higher BMI. Their results were similar to ours. However, they reported that $64.5 \%$ of Yazd students (9-13 years) commuted to the school by walking or biking (14), the present study showed $45.3 \%$ of the Yazd students (12-16 years) used the active way of commuting to the school. It may emanate from that the choice of high quality and facilities school has higher importance rather than near distance for the parents (14). Attention to active transport is so important due to its role in expending a large amount of energy (14). As the previous studies and the present study emphasized, the risk factors of obesity, were varied based on age, race, country, SES, parents' education levels, and gender (11).

The limitations of our study were a) using self-reported data on dietary intake, ST, SB and PA (however, the present questionnaire used in previous studies $(7,8,11,15,22))$, b) the content of dietary intake were not assessed for the current study, the interpretation should be done caution given that this is a cross-sectional study, c) the consideration 
of more confounder factors including the quality and quantity of dietary intake, sleep habits, socioeconomic status (SES), parent history of overweight or obesity, and etc., d) the lack of the data for all year (the data was collected at a particular point of time (only for an academic year), and finally SB was assessed for the activities out of the school time.

Our study had some strong aspects including 1) sample size was nearly large; 2) data were collected from both gender; 3 ) the analysis was performed based on both genders as well as the weekdays and weekend apart from all week; 4) the evaluation of the relationship between overweight or obesity with daily energy intake, PA and the times spent on ST, HT, and SB; 5) the analysis for abdominal obesity was performed (due to the similarity to the present results did not show); 6) the presence of the qualified and same assessors while filling in the questionnaire allowed adolescents to clarify uncertainties and reduce the biases; and finally, the data for ST and SB was comprehensive.

According to the current and previous findings $(3-7,11,13,15)$, it seems to be necessary that policymakers should take the measures to modify lifestyles to reduce the prevalence of overweight or obesity during adolescence.

It was suggested performing a large and comprehensive study due to collecting the data for all year (academic and nonacademic year), as well as at the new situation with the COVID-19 (the presence of quarantine, mandatory online education, and the more accessible to cyberspace) and evaluating more risk factors of obesity in the different region of the country given that the risk factors of overweight or obesity were too wide (11).

\section{Conclusion}

The prevalence of SB, ST, overweight or obesity, abdominal obesity, and low PA was common among Yazd students. In the current study, the school days and weekends' HT and the school days' SB were shown a higher chance of overweight or obesity in the girls. Among boys, only the school days' SB played a more important role rather than other sedentary activities linked to overweight or obesity. The school days' HT and SB and the weekends' HT were linked to overweight or obesity. Among the student as well as both genders, the daily energy intake, PA, and access to the yard were related to overweight or obesity. Moreover, younger age and family size were the remarkable risk factors of overweight or obesity among all the students and boys. The walking or biking to the school and back was reversely related to overweight or obesity only among all the students.

\section{Declarations}

\section{Ethical approval and consent to participate}

The study protocol was approved by the Research Ethical Committee of Ahvaz Jundishapur University of Medical Sciences (IR.AJUMS.REC.1396.1087). The coordination and agreement were made with the Education Department of Yazd. The written informed consent was obtained from the students and their parents to participate in this study after receiving a complete explanation of the study protocols and objectives.

\section{Consent for publication}

The authors affirm that human research participants provided informed consent for publication of their data.

\section{Availability of data and materials}

The datasets used and/or analyzed during the current study are available from the corresponding author on reasonable request. 


\section{Competing interests}

The authors declare that there are no competing interests.

\section{Funding}

This research did not receive any specific grant from funding agencies in the public, commercial, or not-for-profit sectors.

\section{Authors' contributions}

Hassan Mozaffari-Khosravi, Majid Karandish and Maryam Azhdari designed the research; Maryam Azhdari were responsible for the data collection; Maryam Azhdari and Ali Mohammad Hadianfard analyzed the data; Maryam Azhdari and Ali Mohammad Hadianfard were involved in drafting the paper. All of the authors read and approved the final paper.

\section{Acknowledgements}

We thank the cooperation of Yazd province's Education and Training administration, high schools and their students to participate in this project. Moreover, we thank the assistance researchers (Shamim Shams-Rad, Mahtab Tabatabaie, Farhang Mirzavandi, and Siavash Babaie).

\section{References}

1. https://www.who.int/news-room/q-a-detail/noncommunicable-diseases-childhood-overweight-and-obesity 2020 [

2. (https://www.who.int/news-room/fact-sheets/detail/obesity-and-overweight) 2020 [

3. Karandish M, Mozaffari-Khosravi H, Hadianfard AM, Azhdari M, Amiri R, Mirzavandi F, et al. Distribution of Nutrients in Breakfast and Midmorning Snacks among Overweight or Obese Adolescents of Yazd, Iran. Journal of Nutrition and Food Security. 2020;5(4):306-15.

4. Al-Thani M, Al-Thani A, Alyafei S, Al-Kuwari M, Al-Chetachi W, Khalifa S, et al. Prevalence of physical activity and sedentary-related behaviors among adolescents: data from the Qatar National School Survey. Public Health. 2018;160:150-5.

5. Godakanda I, Abeysena C, Lokubalasooriya A. Sedentary behavior during leisure time, physical activity and dietary habits as risk factors of overweight among school children aged 14-15 years: case control study. BMC research notes. 2018;11(1):186.

6. Sisson SB, Broyles ST, Baker BL, Katzmarzyk PT. Screen time, physical activity, and overweight in US youth: National Survey of Children's Health 2003. Journal of Adolescent Health. 2010;47(3):309-11.

7. Mozafarian N, Motlagh ME, Heshmat R, Karimi S, Mansourian M, Mohebpour F, et al. Factors associated with screen time in Iranian children and adolescents: the CASPIAN-IV study. International journal of preventive medicine. 2017;8.

8. Kelishadi R, Qorbani M, Djalalinia S, Sheidaei A, Rezaei F, Arefirad T, et al. Physical inactivity and associated factors in Iranian children and adolescents: the Weight Disorders Survey of the CASPIAN-IV study. Journal of cardiovascular and thoracic research. 2017;9(1):41.

9. Fang K, Mu M, Liu K, He Y. Screen time and childhood overweight/obesity: A systematic review and metaanalysis. Child: care, health and development. 2019;45(5):744-53. 
10. Lourenço CL, da Silva VD, Mendes EL. Prevalence and associated factors with insufficient leisure-time physical activity of adolescents: results of a cross-sectional school population-based study. Revista sobre la infancia y la adolescencia. 2020(19):1-19.

11. Górnicka M, Hamulka J, Wadolowska L, Kowalkowska J, Kostyra E, Tomaszewska M, et al. Activity-Inactivity Patterns, Screen Time, and Physical Activity: The Association with Overweight, Central Obesity and Muscle Strength in Polish Teenagers. Report from the ABC of Healthy Eating Study. International journal of environmental research and public health. 2020;17(21):7842.

12. Omorou AY, Manneville F, Langlois J, Legrand K, Böhme P, Muller L, et al. Physical activity rather than sedentary behaviour is socially determined in French adolescents with overweight and obesity. Preventive medicine. 2020;134:106043.

13. Mozaffari-Khosravi H, Karandish M, Hadianfard AM, Azhdari M, Sheikhi L, Tabatabaie M, et al. The relationship between sleep quality and breakfast, mid-morning snack, and dinner and physical activity habits among adolescents: a cross-sectional study in Yazd, Iran. Sleep and Biological Rhythms. 2020:1-6.

14. Gholami S, Rahmanian M, Jam Ashkezari S, Hazar N, Aghaee-Meybody SMR, Namiranian N. The Prevalence of Obesity and Overweight and Its Relevance to Transportation Among Primary School Students: Yazd, Iran; 2015. International Journal of School Health. 2019;6(2):1-6.

15. Kowalski KC, Crocker PR, Donen RM. The physical activity questionnaire for older children (PAQ-C) and adolescents (PAQ-A) manual. College of Kinesiology, University of Saskatchewan. 2004;87(1):1-38.

16. Adeniyi AF, Okafor NC, Adeniyi CY. Depression and physical activity in a sample of nigerian adolescents: levels, relationships and predictors. Child and adolescent psychiatry and mental health. 2011;5(1):1-10.

17. Onis Md, Onyango AW, Borghi E, Siyam A, Nishida C, Siekmann J. Development of a WHO growth reference for school-aged children and adolescents. Bulletin of the World health Organization. 2007;85:660-7.

18. Xi B, Zong Xn, Kelishadi R, Litwin M, Hong YM, Poh BK, et al. International waist circumference percentile cutoffs for central obesity in children and adolescents aged 6 to 18 years. The Journal of Clinical Endocrinology \& Metabolism. 2020;105(4):e1569-e83.

19. Amiri P, Naseri P, Vahedi-Notash G, Jalali-Farahani S, Mehrabi Y, Hamzavi-Zarghani N, et al. Trends of low physical activity among Iranian adolescents across urban and rural areas during 2006-2011. Scientific reports. 2020;10(1):1-7.

20. Jenabi E, Khazaei S. Trends in obesity among iranian children and adolescents: 2000-2016. The Journal of Tehran University Heart Center. 2020;15(1):41.

21. Keane E, Li X, Harrington JM, Fitzgerald AP, Perry IJ, Kearney PM. Physical activity, sedentary behavior and the risk of overweight and obesity in school-aged children. Pediatric exercise science. 2017;29(3):408-18.

22. Kelishadi R, Motlagh ME, Bahreynian M, Gharavi MJ, Kabir K, Ardalan G, et al. Methodology and early findings of the assessment of determinants of weight disorders among Iranian children and adolescents: The childhood and adolescence surveillance and prevention of adult Noncommunicable Disease-IV study. International Journal of Preventive Medicine. 2015;6. 